\section{SOI: $1.1 /$ TAS $\quad$ DOI: $10.15863 /$ TAS International Scientific Journal Theoretical \& Applied Science}

p-ISSN: 2308-4944 (print) e-ISSN: 2409-0085 (online)

Year: 2015 Issue: 07 Volume: 27

Published: $30.07 .2015 \quad$ http://T-Science.org
Nataliia Sergeevna Remez doctor of technical sciences, professor, Professor of the Environmental Engineering Department IEE NTUU “KPI”, Ukraine

Tatiana Andreevna Osipova postgraduate student

IEE NTUU “KPI”, Ukraine osipova_tetiana@ukr.net

SECTION 7. Mechanics and machine construction.

\title{
THE PREDICTION OF USING MSW LANDFILL AS A BASE OF CONSTRUCTIONS
}

\begin{abstract}
The article describes the prediction of landfill settlement carried out by numerical simulations based on the stress-strain state of the underlying soil for the future using of the landfill as a base of structure. Settlement was calculated for landfills, which based on loam, clay and sand. For the first time was proposed to take into account the soil,which lies in the base of municipal solid waste landfill as the one of the main components of the landfill.

Key words: settlement, municipal solid waste, landfill, compression.

Language: Russian

Citation: Remez NS, Osipova TA (2015) THE PREDICTION OF USING MSW LANDFILL AS A BASE OF CONSTRUCTIONS. ISJ Theoretical \& Applied Science 07 (27): 34-39.

Soi: http://s-o-i.org/1.1/TAS-07-27-6 Doi: crossef http://dx.doi.org/10.15863/TAS.2015.07.27.6

\section{ПРОГНОЗИРОВАНИЕ ИСПОЛЬЗОВАНИЯ ПОЛИГОНОВ ТБО В КАЧЕСТВЕ ОСНОВАНИЯ СООРУЖЕНИЯ}

Аннотация: Прогнозирование осадки полигонов твердых бытовых отходов осуществлялось с помощью численного моделирования с учетом напряженно-деформированного состояния подстилающего грунтового массива для использования полигона в качестве основания сооружения. Осадка рассчитана для полигонов, в основе которых суглинок, глинистые и песчаные грунты. В работе впервые предлагается учитывать грунт основания полигона, являющийся одним из основных составляющих полигона.
\end{abstract}

Ключевые слова: осадка, твердые бытовые отходы, полигон ТБО, компрессия.

Актуальность работы. Украина занимает одно из первых мест в мире по количеству бытового мусора на душу населения. Под полигоны твердых бытовых отходов (ТБО) и свалки отведено свыше 160 тыс. га земель. В Украине ежегодно образуется более 10 млн. т отходов, из которых более чем 90 \% попадает на полигоны. Общее количество санкционированных полигонов и свалок в Украине - около 700. Наибольшие площади под полигоны отведены в Днепропетровской области (140 га), Донецкой области (330 га), Одесской области (195 га), Запорожской области (153 га) и Луганской области (129 га). После закрытия полигона или свалки остаются огромные площади земель, которые не используются. В связи с постоянным увеличением объемов отходов и, как следствие, увеличение площадей, отводимых под полигоны, а также с интенсивным ростом городов и необходимостью отвода новых земель под строительство, остро встает вопрос об устойчивости полигонов и их возможном использовании в дальнейшем как основания для инженерных сооружений.

Полигоны представляют собой очень сложные системы, в которых множество процессов протекают одновременно. Образования свалочного газа меняет давление газа и жидкости в теле полигона, которое может повлиять на пористость, общее напряжение, что в свою очередь вызывает деформации, в первую очередь осадки. Эти деформации негативно влияют на целостность любой структуры, построенной на основе закрытой свалки.

Непредвиденные осадки в конечном счете приводят к ряду проблем, таких как образование трещин в покрывающем слое, повреждения систем сбора газа и жидкостей и дренажных систем, оползней, приводящих к катастрофическим последствиям и вызывают 
разрушение конструкций и даже гибель людей [2].

После закрытия полигона возможно его использование в качестве основы для сооружений и конструкций, в частности спортивных площадок, заповедников, автостоянок, промышленных парков, мест отдыха и т. д. Такая ситуация ставит перед учеными задачу по оценке и прогнозированию устойчивости свалки в качестве основы сооружений.

Анализ литературных источников показал, что экспериментальные методики оценки устойчивости свалки являются затратными и эффективны только для конкретных условий. Например, метод обратного анализа базируется на учете свойств уже разрушенных свалок, и не является удовлетворительным для других в связи с отличием состава отходов, природных условий, свойств слоев и подстилающего грунтового массива. В свою очередь с помощью лабораторных анализов не удается отобразить условия полигона, в том числе захватить в одном образце все слои и учесть их геотехнические и физико-механические свойства. Поэтому для учета наряжено-деформированного состояния слоев полигона и подстилающего грунтового массива и его характеристик целесообразно применять математическое моделирование.

Математические модели, прогнозирующие осадку можно разделить на реологические модели, эмпирические модели, модели, базирующиеся на механике грунтов и модели, учитывающие биодеградацию.

Парк Г.И. и Ли С.Р. предложили модель осадки, учитывающей зависимую от времени биодеградацию отходов. Предполагается, что скорость осадки выражается через множество осадок, прямо пропорциональную количеству твердых веществ, которые разлагаются. Растворения органических материалов определяется с использованием уравнения кинетики первого порядка. Сумма двух условий дает общую деформацию сжатия. Однако, определение кинетических коэффициентов или констант гидролиза, а также их изменение в условиях окружающей среды является очень сложным [9].

Эмпирические модели пытаются имитировать общее поведение отходов путем корректировки эмпирических параметров для конкретного участка. Для аппроксимации в основном используются следующие математические функции: логарифмическая функция, степенная функция ползучести и гиперболическая функция осадки.

Маркес А. разработал составляющую реологическую модель для учета первичных и вторичных механизмов сжатия, которые руководствуются реологическими параметрами, учитывающимися при деградации отходов. Первичная компрессия называется «мгновенной компрессией», которая не зависит от времени. Это основано на наблюдении, что соответствующий процесс является линейным для кривых, коэффициент пористости которых является функцией логарифма приложенного напряжения [4].

Общей чертой этих и других моделей является то, что они учитывают только твердые бытовые отходы, их поведение и свойства, пренебрегая такой важной составляющей полигона, как грунты, лежащие в его основе. Именно от типа, прочности, геотехнических свойств подстилающего грунта зависит устойчивость полигона, поскольку наибольшую нагрузку испытывает именно он. Основываясь на наблюдениях крутых склонов свалок, которые остаются стабильными, можно сделать вывод, что основное внимание при анализе устойчивости полигона должно быть уделено материалам, которые лежат в основе ТБО. В настоящее время этот вопрос не изучен.

Для прогнозирования оценки устойчивости полигона предлагается изучение его осадки с обязательным исследованием напряженнодеформированного состояния подстилающего грунтового основания, которое моделируется с учетом поэтапной нагрузки каждого слоя отходами. Это позволит оценить возможность использования полигона в качестве основы здания или конструкции с учетом типа грунта.

Цель работы - установление зависимости осадки закрытого полигона ТБО от подстилающих грунтов для прогнозирования возможности использования его в качестве основания сооружения.

МАТЕРИАЛЫ И РЕЗУЛЬТАТЫ ИССЛЕДОВАНИЯ. Для прогнозирования осадки закрытого полигона ТБО при его использовании в качестве основания дорожного покрытия было проведено математическое моделирование. Покрывающий и подстилающий слои моделировались с помощью модели КулонаMopa [3]. При этом тело полигона моделировалось слабым грунтом с учетом ползучести, использовалась модель Soft Soil Creep (SSC). В настоящее время данная модель наиболее полно описывает такие свойства слабого грунта, как зависящую от напряжения жесткость, а также вторичную компрессию с учетом ползучести .

Полная объемная деформация $\varepsilon_{v}$, вызванная ростом значения эффективных напряжений с начального значения $p_{0}$ ' до $p$ ' за период времени $t_{c}+t^{\prime}$, выражается в виде суммы упругой составляющей $\varepsilon_{v}^{e}$ и вязкопластической составляющей $\varepsilon_{v}^{v p}$. Вязкопластическая составляющая состоит из деформации во время 
консолидации $\varepsilon_{v}^{v p}{ }_{c}$ и после консолидации $\varepsilon_{v}^{v p}{ }_{a c}$. Связь между деформациями выражается в следующем виде:

$$
\varepsilon_{v}=\varepsilon_{v}^{e}+\varepsilon_{v}^{v p}+\varepsilon_{v a c}^{v p}
$$

где $\varepsilon_{v}$ - полная объемная деформация; $\varepsilon_{v}^{e}$ упругая составляющая деформации; $\varepsilon_{v}^{v p}$ вязкопластическая составляющая деформации во время консолидации; $\varepsilon_{v}^{v p}{ }_{a c}$ - вязкопластическая составляющая деформации после завершения консолидации.

$$
\begin{gathered}
\varepsilon_{v}^{e}=\kappa^{*} \ln \left(\frac{p^{\prime}}{p_{0}^{\prime}}\right) ; \\
\varepsilon_{v}^{v p}=\left(\lambda^{*}-\kappa^{*}\right) \ln \left(\frac{p_{p c}^{\prime}}{p_{0}^{\prime}}\right) ; \\
\varepsilon_{v a c}^{v p}=\mu^{*} \ln \left(\frac{\tau_{c}+t^{\prime}}{\tau_{c}}\right),
\end{gathered}
$$

где $\kappa^{*}$ - модифицированный коэффициент набухания; $\lambda *$ - модифицированный коэффициент компрессии (сжатия); $\mu^{*}$ - модифицированный коэффициент ползучести; $t_{c}-$ время окончания первичной консолидации; $t$ - время, прошедшее с начала загрузки полигона; $\tau_{c}-$ время консолидации; $p_{0}$ ' - начальное эффективное напряжение; $p$ ' - эффективное напряжение; $p_{p c}^{\prime}-$ эффективное преконсолидационное напряжение [10, c. 699].

Отношение параметров модели к международно-нормированным параметрам следующее:

$$
\begin{gathered}
\mu^{*}=\frac{C_{\alpha}}{2,3\left(1+e_{0}\right)} ; \lambda^{*}=\frac{C_{c}}{2,3\left(1+e_{0}\right)} ; \\
\kappa^{*}=\frac{2 C_{s}}{2,3\left(1+e_{0}\right)},
\end{gathered}
$$

где $C_{c}-$ коэффициент компрессии; $C_{S}-$ коэффициент набухания; $\mathrm{C}_{\alpha}-$ коэффициент ползучести.

Эквивалентное напряжение выражается с помощью формулы:

$$
p_{p}^{e q}=p^{\prime}+\frac{q^{2}}{M^{2}\left(p^{\prime}+c^{\prime} \operatorname{ctg} \varphi\right)},
$$

где $c$ - сцепление; $\varphi$ - угол внутреннего трения; $q$ - напряжение; $p$ ' - преконсолидационное напряжение; $p_{p}{ }^{e q} \quad$ - эквивалентное преконсолидационное изотропное напряжение; $M$ - коэффициент, который определяется по формуле:

$$
M=3 \sqrt{\frac{\left(1-K_{0}^{n c}\right)^{2}}{\left(1+2 K_{0}^{n c}\right)^{2}}+\frac{\left(1-K_{0}^{n c}\right)\left(1-2 v_{u r}\right)\left(\frac{\lambda^{*}}{\kappa^{*}}-1\right)}{\left(1+2 K_{0}^{n c}\right)\left(1-2 v_{u r}\right) \frac{\lambda^{*}}{\kappa^{*}}-\left(1-K_{0}^{n c}\right)\left(1+v_{u r}\right)}},
$$

где $v_{u r}-$ коэффициент Пуассона; $K_{0}^{n c}-$ коэффициент бокового напряжения при нормальной консолидации.

Гидродинамические аспекты проблемы состоят в учете фильтрационных сил, действующих на скелет грунтовой среды, и параметров взаимодействия жидкой и твердой фаз грунта (давления, напряжения и пористости) в процессе консолидации. В предположении безвихревого течения фильтрационного потока и распределения сил сопротивления равномерно по сечению элемента используется обобщеный закон Дарси и уравнение неразрывности. Принимается, что сжимаемость скелета и поровой жидкости мала, что приводит к линейной зависимости пористости грунта от давления.

Взаимодействие скелета грунта и жидкости характеризуется объемной силой, пропорциональной градиенту напора. Тогда при совместном действии на скелет грунта фильтрационных и гравитационных сил напряженное состояние определяется из уравнений равновесия элементов грунтовой области, которые получены путем проецирования приложенных сил на оси координат. Уравнения дополняются начальными и граничными условиями.

Полигон, для которого было проведено моделирование, состоит из десяти слоев отходов, толщина каждого слоя 3 м. Осадка определялась c учетом пошагового нагружения полигона спустя 30 лет после его закрытия. Для численного решения задачи использовался метод конечных элементов. Расчетная область покрывалась треугольными элементами (рис.1). 


\begin{tabular}{|c|c|c|c|c|c|c|}
\hline Impact Factor: & $\begin{array}{l}\text { ISRA (India) } \\
\text { ISI (Dubai, UAE } \\
\text { GIF (Australia) } \\
\text { JIF }\end{array}$ & $\begin{array}{l}=1.344 \\
=0.829 \\
=0.356 \\
=1.500\end{array}$ & $\begin{array}{l}\text { SIS (USA) } \\
\text { PИHЦ (Russia) } \\
\text { ESJI (KZ) } \\
\text { SJIF (Morocco) }\end{array}$ & $\begin{array}{l}=0.912 \\
=0.179 \\
=1.042 \\
=2.031\end{array}$ & ICV (Poland) & $=6.630$ \\
\hline
\end{tabular}

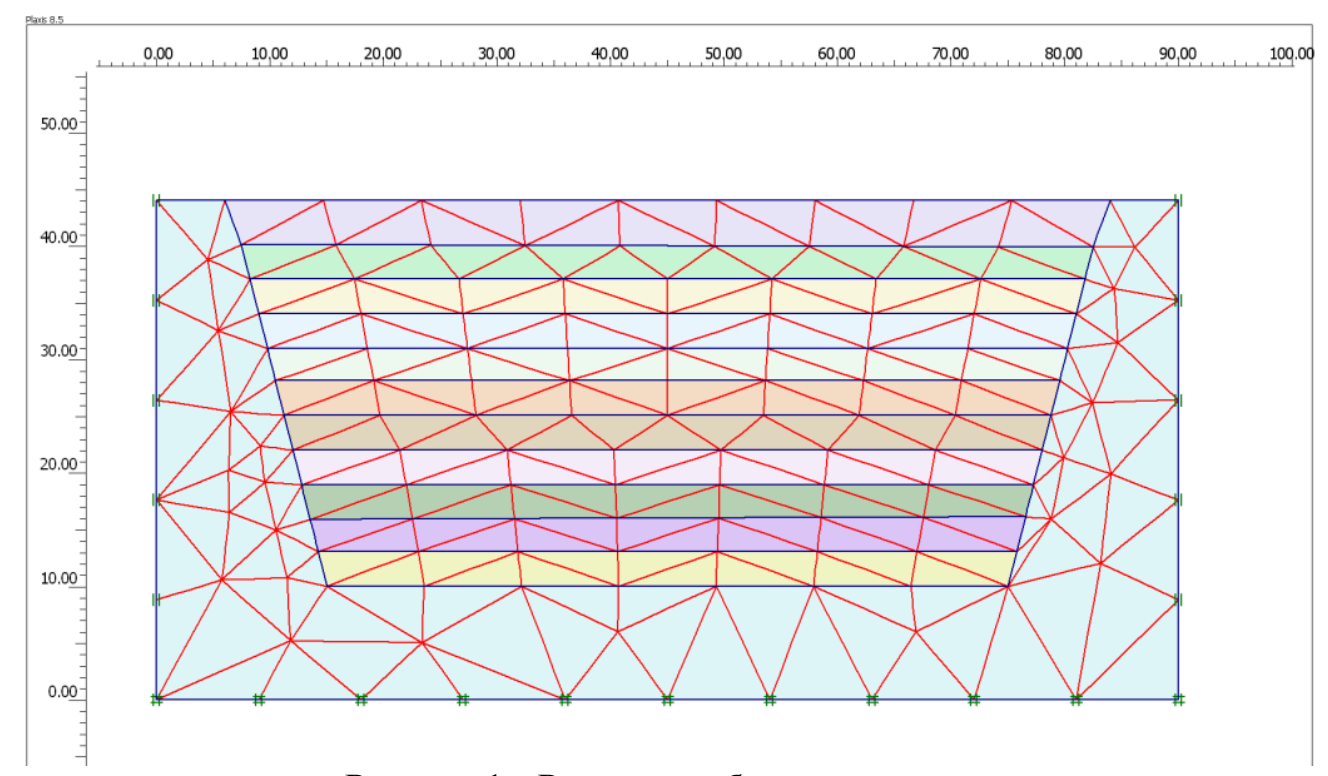

Рисунок 1 - Расчетная область полигона.

Были рассчитаны 3 варианта осадки полигона при условии разных подстилающих слоев грунта: глина, суглинок и песок.
Параметры подстилающих грунтов, которые принимались при моделировании, представлены в таблице 1.

Таблица 1

Параметры подстилающих грунтов, которые принимались при моделировании.

\begin{tabular}{|l|c|c|c|}
\hline \multicolumn{1}{|c|}{ Параметр } & Песок & Суглинок & Глина \\
\hline Модуль деформации, $E_{\text {ref }}$ & 18000 & 10000 & 9000 \\
\hline Коэффициент Пуассона, $v$ & 0,34 & 0,34 & 0,34 \\
\hline Удельный вес грунта, $\gamma_{\text {unsat }}$ & 18,0 & 13 & 19,0 \\
\hline Удельный вес водонасыщенного грунта, $\gamma_{\text {sat }}$ & 20,7 & 14,6 & 21,8 \\
\hline Коэффициент фильтрации в горизонтальном направлении, $k_{x}$ & 0,5 & 0,006 & 0,004 \\
\hline Коэффициент фильтрации в вертикальном направлении, $k_{y}$ & 0,5 & 0,006 & 0,004 \\
\hline Сцепление, $c$ & 2 & 13 & 17 \\
\hline Угол внутреннего трения, $\varphi$ & 31 & 14 & 13 \\
\hline
\end{tabular}

Деформированная сетка полигона с песчаным грунтом основания представлена на рис.2. Вертикальные деформации полигона с песчаным грунтом основания представлены на рис.3. В результате численного расчета установлено, что максимальная вертикальная деформация составила 4,95 м.

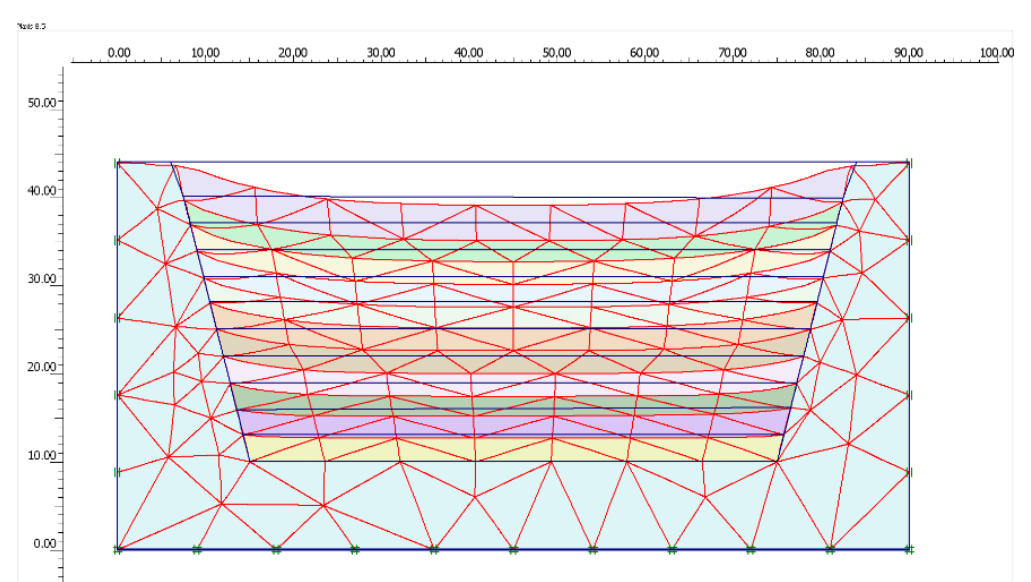

Рисунок 2 - Деформированная стека полигона с песчаным грунтом основания.

ISPC Intelligent technologies, 


\begin{tabular}{|c|c|c|c|c|c|c|}
\hline Impact Factor: & $\begin{array}{l}\text { ISRA (India) } \\
\text { ISI (Dubai, UAE } \\
\text { GIF (Australia) } \\
\text { JIF }\end{array}$ & $\begin{array}{l}=1.344 \\
=0.829 \\
=0.356 \\
=1.500\end{array}$ & $\begin{array}{l}\text { SIS (USA) } \\
\text { PИHЦ (Russia) } \\
\text { ESJI (KZ) } \\
\text { SJIF (Morocco) }\end{array}$ & $\begin{array}{l}=0.912 \\
=0.179 \\
=1.042 \\
=2.031\end{array}$ & ICV (Poland) & $=6.630$ \\
\hline
\end{tabular}

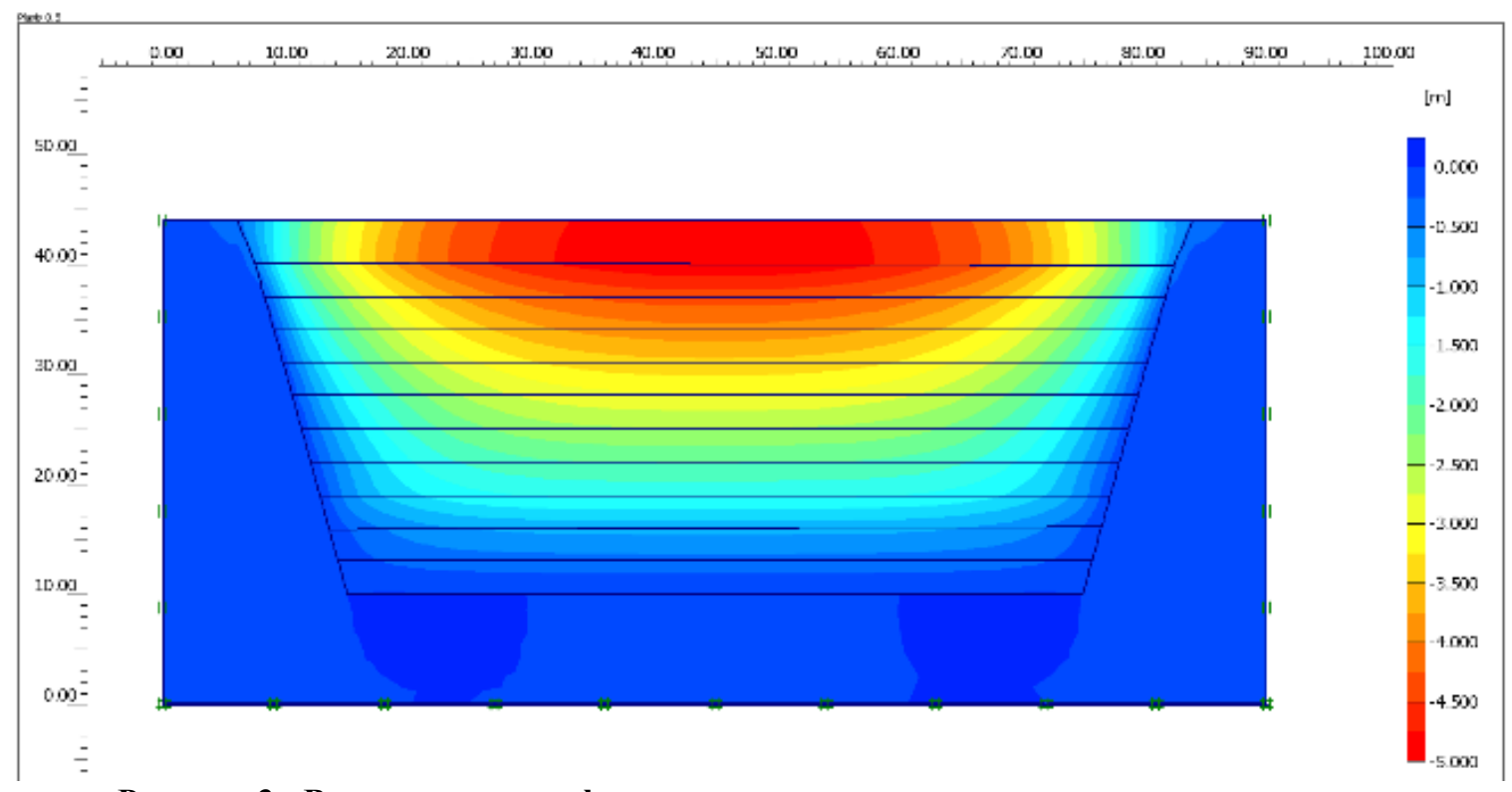

Рисунок 3 - Вертикальные деформации полигона с песчаным грунтом основания.

Если подстилающий грунт - глина (рис.4), то можно наблюдать, что достигаются значительно меньшие деформации (3,83 м).

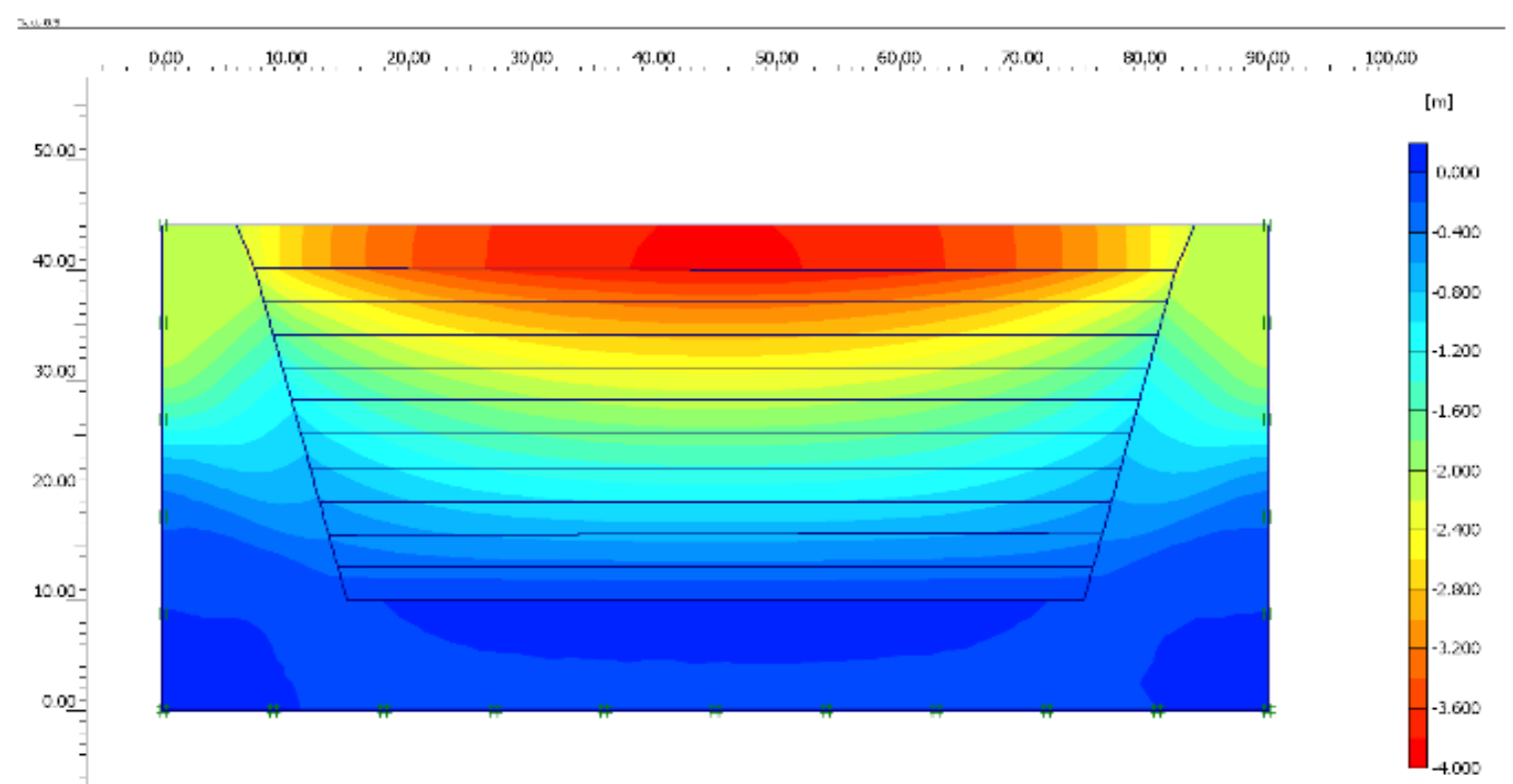

Рисунок 4 - Вертикальные деформации полигона с глинистым грунтом основания.

Также был проведен расчет осадки с суглинком в качестве подстилающего слоя, максимальная вертикальная деформация составила 4,47 м.

В результате проведенных исследований установлено, что при одинаковых характеристиках отходов осадка полигона с глинистым грунтом основания на 23\% меньше, чем у полигона с песчаным грунтом основания и на $14 \%$ меньше чем с суглинком, в качестве грунта основания полигона.

\section{Выводы:}

Из проведенных исследований следует:

1) закрытые полигоны занимают огромные площади, поэтому при их закрытии возникает необходимость их использования в качестве оснований различных сооружений, что невозможно без достоверного прогноза их устойчивости;

2) впервые предложено учитывать при расчете устойчивости полигона подстилающий

ISPC Intelligent technologies,

Marseille, France 
грунт, так как он является одним из основных условий при формировании осадки;

3) разработана эффективная методика расчета осадки полигона ТБО, основанная на численном моделировании напряженнодеформированного состояния полигона и подстилающего грунта с использованием моделей SSC для полигона и Кулона-Мора для грунтового основания с применением метода конечны элементов;
4) в результате численного решения установлено, что при одинаковых условиях полигона, если подстилающий слой представлен глиной, то достигаются значительно меньшие осадки по сравнению с более слабым грунтом (на $23 \%$ меньше, чем с песком и на $14 \%$ меньше, чем с суглинком в качестве основания), что доказывает, что при прогнозировании осадки полигона для его использования в качестве основания сооружения, необходимо учитывать подстилающий грунтовый массив.

\section{References:}

1. Di Palma, P. Ferrantelli, C. Merli, E. Petrucci (2002) Treatment of industrial landfill leachate by means of evaporation and reverse osmosis, Waste Manage. 22 (2002) 951-955.

2. Sivakumar Babu GL, Reddy KR, Chouskey SK, Kulkarni HS (2010) Prediction of Long-term Municipal Solid Waste Landfill Settlement Using Constitutive Model. Practice Periodical of Hazardous, Toxic and Radioactive Waste Management. New York, ASCE, 2010, vol. 14, no. 2, pp. 139-150. DOI: http://dx.doi.org/10.1061/ (ASCE)HZ.1944-8376.0000024.

3. Vermeer PA, Neher HP (1999) A Soft Soil Model that Accounts for Creep. Proc. Int. Symp. "Beyond 2000 in Computational Geotechnics", Amsterdam, pp. 249-261, Balkema, Rotterdam.

4. Marques ACM, Vilar OM (2003) "Composite comopressibility model for municipal solide waste." J.Geotech.Geoenviron.eng., 129(4), 372-378.

5. Behnam Fatahi (2013) Improving Geotechnical Properties of Closed Landfills for Redevelopment Using Fly Ash and Quicklime,
University of Technology, Sydney. Faculty of Engineering and Information Technology, 544 p.

6. Sowers GF (1973) "Settlement of waste disposal fills." Proc., 8th Int. Conf. on Soil Mechanics and Foundation Engineering, Moscow, Russia, Vol. 2, 207-210.

7. Yen BC, Scanlon BS (1975) "Sanitary landfill settlement rates." J. Geotech. Eng., 101(5), 475-487.

8. Gibson RE, Lo KY (1961) "A theory of soils exhibiting secondary compression." Acta Polytech. Scand., C(10), 1-15.

9. Park HI, Lee SR (1997) "Long-term settlement behavior of landfills with refuse decomposition." J. Resour. Manage. Technol., 24(4), 159-165.

10. Rangeard D, Zentar R, Abriak NE (2004) Influence of soil model on the analysis of pressuremeter test. In proceedings of Int. Conf. on Numer. Models in Geomech., NUMOG IX, 699-705. 